\title{
Some patterns in the history of violence
}

\author{
FRANK H. DENTON1
}

The RAND Corporation

and

WARREN PHILLIPS

Mental Health Research Institute, University of Michigan

\section{Introduction}

This paper reports on progress made in a research project aimed at describing systematic trends in the violence between political groups. The report is in two parts. Part one describes the formulation of an empirical test for the existence of (1) a short-term (15-30 years) and (2) a longterm (80-120 years) periodic fluctuation in the historical occurrence of war. Although some background is given about why such a test should be made, the research described in part one is based, largely, on empirical rather than theoretical generalizations. That is, not much attention is given to the "why" of such patterns.

The tests tend to confirm the existence of the expected patterns. Obviously, it is desirable to go beyond the simple observation that an empirical regularity exists to some explanation of the forces leading to that regularity. The available data do provide clues as to possible explanations. The second part of the paper speculates about several possible reasons for these patterns.

\footnotetext{
${ }^{1}$ Any views expressed in this paper are those of the author. They should not be interpreted as reflecting the views of The RAND Corporation or the official opinion of any of its governmental or private research sponsors. Papers are reproduced by The RAND Corporation as a courtesy to members of its staff.
}

The explanations are consistent with the data, but their testing must await the collection of historical material broader in scope than that now available.

\section{Transformations of the International System}

Among the effects of the rise to prominence of general systems models in the social sciences, especially international relations, has been the focusing of attention on transformations of the system. The idea of systematic analysis of changes in the system, although new in its particular form, is based on a long history of speculation about evolutionary or cyclical transformations in the social experience. Perhaps influenced by the unrest, violence, and (at times) chaos of this half-century, recent writers such as Spengler, Toynbee, and Sorokin have largely discarded evolutionary "development" in favor of large cyclic movements in history.

Data which would permit the empirical testing of these speculative theories about system changes are not always readily obtainable. In order to perform such tests, data are needed which cover extended periods of time and which are collected in a systematic manner. Records of the incidence of wars represent one of the few types of data meeting these requirements. 
Some previous research has been done in this area. Sorokin, for one, has attempted in a semi-systematic manner to test for cyclic patterns in war. He expresses a very negative view about the occurrence of cyclical patterns as a result of this examination (1957, pp. 534-604). Richard Rosecrance, in an excellent volume, examined patterns of diplomacy for system changes. Although he was apparently not looking for a cyclic pattern, his findings suggest such a pattern (1963).

Other collections of statistics on war have formed the basis for exploratory examinations for possible time-dependent patterns. Lewis Richardson investigated the possibility of a general trend toward a greater number of wars in the international system. He chose a run of 432 years, divided it in half, and demonstrated that no such trend existed in the data examined. His examination of the frequency of outbreak of war on an annual basis indicated a random fluctuation over time which could be well approximated by a Poisson distribution. Groupings of the data into longer periods (longer than one year and less than 230 years) do, however, indicate fluctuations which cannot be explained as random occurrences (1960, pp. 139-40).

J. E. Moyal (1949) reexamined Quincy Wright's list of wars in order to test two hypotheses. His first hypothesis states that the number of wars in a given period may be correlated with the number of wars in a past period, separated by a fixed interval. Moyal finds that, with time lags of five and 15 years, there is a distinctly significant autocorrelation in the outbreak of war.

Moyal's second hypothesis assumed a slow fluctuation in the probability of an outbreak of war. He averaged the number of outbreaks of war using a fifty-year running average. On plotting this running average against the central date, a marked periodic variation in the outbreak of wars was discernible, the half-life being about 100 years.

These findings, as well as those in previous research by one of the authors, suggest that periods of relative peacefulness tend to alternate with relatively warlike periods. Such a regular fluctuation in the intensity of war is of interest in itself; however, these earlier findings also suggest that violence in the international system is to a great extent a reflection of the political state of affairs of the system. More specifically, when the system is characterized by instability and intense political disputes it is also characterized by widespread and intense violence. Thus, to some extent, changes in the state of the international political system can be observed by observing changes in the amount and type of violence in the system. Again, more precisely, it is assumed that the data on war go beyond just indicating the amount of violence; these data reflect something about international politics as well. This assumption, critical to the "explanation" of the observed patterns, is discussed in the brief review of previous research in the next section.

\section{Exploratory Analyses}

Two exploratory analyses of systematic trends in violence generated findings which are felt to be relevant to the work reported upon in this analysis. The first study defined the spatial-temporal domain of interest as the internation system from 1820 until 1949 (Denton, 1966). The second study, also by Denton (unpublished), focused on Latin America between 1820 and 1949. The data for both of these studies were taken from Lewis F. Richardson's collection (1960).

In each case one goal of the analysis was to test the data for a periodic upswing in 


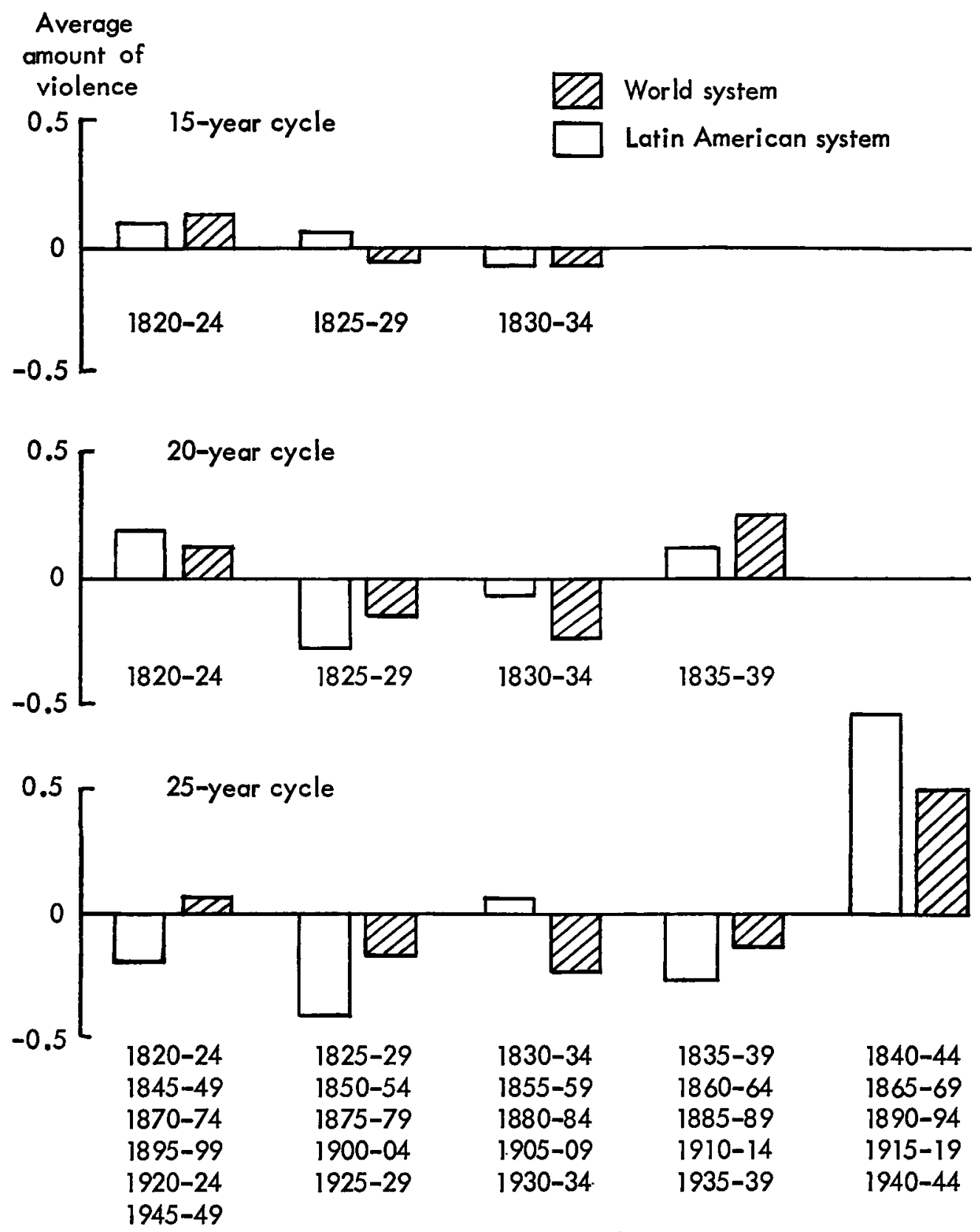

Fig. 1. A generation cycle. 
violence every 15 to 30 years. Since the concept of "upswing in violence" could be represented by one or two large wars as well as by many small wars, the Richardson and Moyal measures of new outbreaks of war did not provide a satisfactory index. Rather a composite "amount of violence" index was formulated from the number of wars, the number of casualties, and the number of participants. ${ }^{2}$

Both studies indicated a definite tendency for a periodic increase in the level of violence about every 25 years.

The level of violence in each of the bars in Figure 1 is found by averaging the level of violence over five-year periods separated by intervals of 15,20 , or 25 years. Thus the first bar in Figure 1, for the 25-year cycle case, is the mean level of violence for the five-year periods: 1820-24, 1845-49, 1870-74, 1895-99, 1920-24, and 1945-49. A pattern with all averages near zero indicates that the amount of war was roughly uniform across time. If a recurring tendency exists for more war at a fixed interval, some averages should deviate significantly from zero. It is readily apparent that these two analyses indicate a tendency for violence to be relatively intense about every 25 years. These findings are surprisingly consistent with Richard Rosecrance's divisions of the temporal dimension of the international political system. ${ }^{3}$

A chi-square test assuming as a null hypothesis an equiprobable distribution of

2 This index is a weighted composite of the three variables indicated. It is formed by a technique called concept mapping (Jones, 1966). Mathematically the index is similar to a "factor" in factor analysis. The values of this index are standardized. That is, the set of index values has a mean of zero and a variance of one.

${ }^{3}$ Denton (1966). This provides some support for the assumed correlation between international politics and international violence. values above and below the mean for each of the five intervals indicated a deviation from equiprobability significant at the .15 level for the world system and at the .04 level for the Latin American system.

In addition to the 25-year cycle indicated above, a longer-term cyclical effect was suggested. Again, known historical patterns are indicated by the trends in the data on war. The relatively turbulent times following the French revolution show a moderate amount of violence. The stable political situation usually associated with the latter part of the 19th century corresponds to a period of low violence in Figure 2. And finally, the 20th century, often referred to as a revolutionary time, is shown as a period of very intense violence.

While the data for this period covered by Richardson (1820-1949) provide a preliminary indication of a longer cyclic pattern, a test for a long-term rise and fall in overall intensity of violence requires a longer period to allow for more than one 80-120 year cycle. Quincy Wright provides a collection of statistics on violence covering the 420 years between 1480 and 1900 (Wright, 1942). This source of data is used for testing the two hypotheses suggested by the exploratory analyses. The remainder of this paper states the propositions which guide the work; delineates the empirical world; lays down the operational procedures; and presents the findings derived from these tasks.

\section{Analysis of Wright's Data}

\section{FORMULATION OF THE PROBLEM}

The exploratory research reported on above suggests two cycles. The first cycle appears to have a period of about 25 years and to be superimposed on one of longer duration. The two hypotheses to be tested are: (1) There is a tendency for an upswing in the level of violence at about 


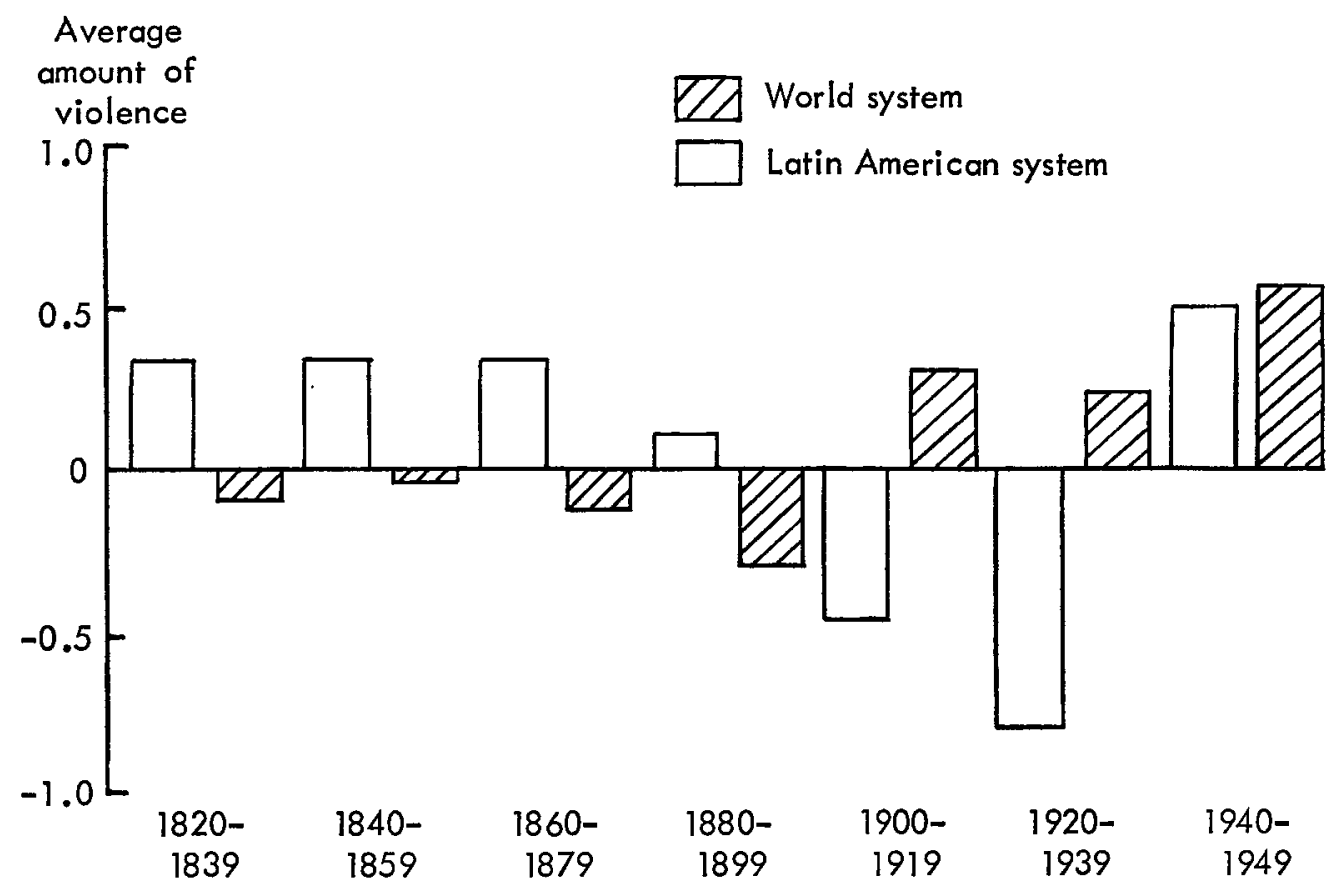

FIc. 2. A suggestion of a longer cycle.

25-year intervals. It might also be expected that the upswing will possess a gradual rise and delcine, perhaps resembling a sine wave. (2) There is a tendency for a 80-120 year cycle in the violence level. This cycle may have a sine-wave pattern. However, a sharp reaction against extreme instability may result in a "saw tooth" effect. That is, the pattern may be a gradual rise followed by a sharp decline.

The data used for testing these hypotheses are taken from Quincy Wright's compilation covering the period 1480-1900. Wright's data include “. . . all hostilities involving members of the family of nations ... which were recognized as states of war in the legal sense or which involved over 50,000 troops" (1942, p. 636). Thus, relatively small incidents of violence not involving a declaration of war are systematically excluded from the tables, contrary to the Richardson data used in the ex- ploratory analysis. For each of his wars, Wright lists the start and end dates, the number of battles, and the primary participants. ${ }^{4}$ Wright also divides wars into four types: (1) defense of civilization; (2) civil; (3) balance-of-power, and (4) imperial (1942, p. 641).

Criticisms have been justly leveled at both Richardson's and Wright's works for the lack of concreteness in the explanation of data-collecting procedures. ${ }^{5}$ Work is now underway in an attempt to replicate and

4 “. . . actual independence before or after the war rather than legal status under international law was the criterion used [for including a participant] . . . . Unsuccessful revolutionists, rebels, or insurgents which lacked even de facto status, except during the war itself, have not been so listed, and many of the small feudal principalities of the Holy Roman Empire have been ignored ...."

${ }^{5}$ See Singer, Small, and Kraft (1965) for a discussion of the merits of these works. 
extend these data in at least two institutions. ${ }^{6}$ This study is conceived of in an iterative sense. More detailed studies can check later on the "truth" of the findings. In any case, the errors in the two data collections are unknown and are probably small when patterns of this nature are being sought.

Two indices are formulated to test the above hypotheses. As in the exploratory studies, an index of the "size" or amount of violence in the system is required to test for the expected periodicities. Secondly, it is felt that the type of war prevalent in the system may be of some value in explaining fluctuations in intensity. Thus variables are included which indicate the relative frequency of the four types of war defined by Professor Wright (see above).

In order to reduce fluctuations caused by random or atypical events when very short time intervals are used, and in order to reduce the necessity for handling many small observations, the 420 -year time interval is divided into 84 five-year periods. ${ }^{7}$ Any war overlapping an interval for more than one year or totally contained in an interval is included in that interval. Thus, a war extending over 20 years might be counted four or five times (in successive intervals). The purpose in doing this is to include all violence existing in the system at a given time, rather than simply outbreaks of war during each period.

The following variables are included as potential indicators of size and type:

\section{Size Indicators:}

(1) Number of wars occurring within or overlapping the time period.

\footnotetext{
'Singer, Small, and Phillips at the University of Michigan, and Denton at the University of Southern California.

${ }^{7}$ This interval length results in four or five observations per period for the shortest cycle hypothesized.
}

(2) The number of political groups having combat during the interval. ${ }^{8}$

(3) Number of groups from (2) divided by the number of nations listed in Wright's charts for that year. This normalizing factor is included to see if it might influence the results.

(4) The total number of participant years of war in the time interval.

(5) The number of battles fought in the time interval. Wright lists only the total battles for a war. For wars extending over more than one period the number of battles is allocated by the percent of the war's participant years which occurred in the given period.

Type Indicators. These indicators are "normalized" for size, since predominance in the system is the desired attribute. Thus the type of war variables are computed as the percent of wars in a time interval that are classified as a given type: (1) percent civil, (2) percent defense of civilization, (3) percent balance of power, and (4) percent imperial.

These items, observed for the 84 time periods, constitute the data for testing the hypotheses. The sample includes 375 wars, and 88 percent of the time periods include at least two wars. Thus, the data as aggregated are sufficiently well distributed to reduce somewhat the fluctuation which might result from occasional atypical events (see Table 1).

SIZE OR AMOUNT OF VIOLENCE INDEX

The primary need in this research is for a valid indicator of size or scope of war in the international system during each of the five-year periods. The five measures indicated above are all felt to be manifestations of the general concept size of violence. That is, a period with much violence can

\footnotetext{
${ }^{8}$ Contrary to Wright's formulation, revolu-
} tionary groups are included. 
TABLE 1

Distribution of Wars OVer the Five-YeAR Perions

\begin{tabular}{cc}
\hline $\begin{array}{c}\text { Number of wars in } \\
\text { the observation period }\end{array}$ & $\begin{array}{c}\text { Number of periods } \\
\text { with indicated } \\
\text { number of wars }\end{array}$ \\
\hline 0 & 1 \\
1 & 9 \\
2 & 10 \\
3 & 14 \\
4 & 12 \\
5 & 10 \\
6 & 8 \\
7 & 7 \\
8 & 8 \\
9 & 5 \\
& 84 \\
\hline
\end{tabular}

typically be expected to have many wars, many participants, many battles, etc. However, it also is possible to have few wars but still have much violence during a fiveyear period if a few large wars occur. Intense violence may also be manifested in many small wars during the period. For these reasons it is felt that no one of these variables is as good an index of "size" as is a combination of them.

An examination of the empirical record indicates that, with the exception of number of battles, these variables do correlate quite highly (Table 2). Since Wright often failed to list any battles for non-European conflicts, this variable was deemed of lower quality and is not used in the index. The high correlations indicate that the occurrence of a "few large" or "many small" wars is uncommon and that the number of belligerents is a reasonably good estimator of the others. However, an index can be formulated which is a still better predictor (has higher correlations). Two methods are used to obtain an index of size: (1) a principal component (factor analysis) fit to the data, and (2) a construct-mapping fit. The construct-mapping routine fits a factor between the four retained variables so that each variable is equidistant from that factor (Jones, 1966). Table 3 gives the correlation of these two indices (or factors) with each of the original variables and with one another. The two fits are essentially the same (correlation of .97) and account for almost the same proportion of variance $(71+$ percent $)$. They are each better predictors than the belligerent variable (67

TABLE 2

Correlation of Size Variables

\begin{tabular}{lccccc}
\hline \hline & \multicolumn{5}{c}{ Variables } \\
\cline { 2 - 6 } & 1 & 2 & 3 & 4 & 5 \\
\hline 1. Number of battles & - & & & & \\
2. Number of belligerents & .36 & - & & & \\
3. Number of belligerents normalized & .25 & .73 & $-\overline{3}$ & - & \\
4. Number of belligerent years & .35 & .85 & .69 & .51 & - \\
5. Number of wars & .05 & .67 & .53 & .51 \\
\hline
\end{tabular}

TABLE 3

Index Fit to the Data

\begin{tabular}{lccccc}
\hline & \multicolumn{5}{c}{ Variables } \\
\cline { 2 - 6 } & $\mathbf{2}$ & $\mathbf{3}$ & $\mathbf{4}$ & $\mathbf{5}$ & $\mathbf{6}$ \\
\hline 6. Principal Component & .84 & .85 & .89 & .79 & - \\
7. Construct Mapping & .84 & .84 & .84 & .84 & .97 \\
\hline
\end{tabular}



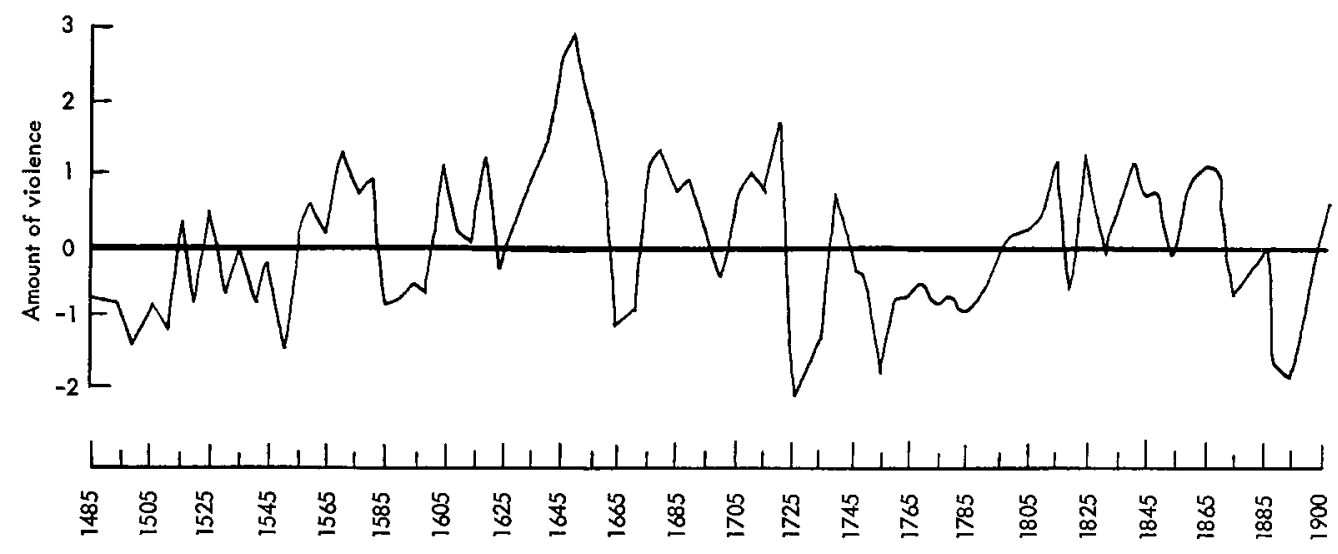

Fic. 3. Amount of violence (Wright's data).

percent of variance), and the constructmapping index is arbitrarily chosen for this analysis.

\section{TWENTY-FIVE YEAR CYCLE}

Figure 3 is a plot of this size-of-war index for the period 1480-1900. Visually it is difficult to note any outstanding trends. An examination of periods 20, 25, and 30 years apart provides little indication of a periodic upswing in violence when the size of conflict variable is divided into periods above and below its mean value (Table 4).

There is some tendency for periods of relatively low violence to occur every 30 years starting in 1490. The hypothesis is in terms of periods of relatively intense violence rather than periods of relative quiet, however.

Returning to Figure 3, the fluctuations do appear to be more rapid for the first half of the period than for the second. The two halves, taken separately, might show a trend which is cancelled out when both halves are combined. Such a periodicity could show some drift across a temporal domain of this length. For example, if the periodicity is explained in terms of a generation or a decision-maker "life time" effect, the increase in man's life span would lead to an expectation of a slower fluctuation in the latter part of the sample. Moreover, if such a cycle is considered as probabilistic rather than deterministic, a rare event of two violent periods exceptionally close to-

TABLE 4

Test for a 25-Year Cycle

\begin{tabular}{llrrrrrr}
\hline \hline & \multicolumn{6}{c}{$\begin{array}{c}\text { Number of periods when } \\
\text { amount-of-war index is }\end{array}$} \\
\hline 20-year & Above mean & 11 & 8 & 12 & 11 & \\
intervals & Below mean & 10 & 13 & 9 & 10 & \\
25-year & Above mean & 9 & 10 & 7 & 8 & 8 & \\
intervals & Below mean & 8 & 7 & 10 & 9 & 8 & \\
30-year & Above mean & 7 & 3 & 8 & 8 & 8 & 8 \\
intervals & Below mean & 7 & 11 & 6 & 6 & 6 & 6 \\
& & 1485 & 1490 & 1495 & 1500 & 1505 & 1510 \\
& & \multicolumn{7}{c}{ Initial Time Period } \\
\hline
\end{tabular}


TABLE 5

Twenty-Year Cycle-Pre-1680

\begin{tabular}{lrrrr}
\hline \hline & \multicolumn{4}{c}{ Number of periods } \\
\hline Above mean & 5 & 4 & 9 & 5 \\
Below mean & 6 & 7 & 2 & 6 \\
& 1485 & 1490 & 1495 & 1500 \\
Average value of & & & & \\
amount-of-war & .07 & -.08 & .30 & .08 \\
\hline
\end{tabular}

gether (or far apart) could result in a shift in the phase of the cycle, giving a cancelling effect over a period of this length. To test for these possibilities the data are divided into pre-1680 and post-1680 groups.

The data for the period prior to 1680 indicate an upswing in violence about every 20 years, starting with the period ending in 1495 (Table 5). After 1680 there is a history of relatively high violence about every 30 years starting in the time period ending in 1690 (Table 6).

The data are generally supportive of the hypothesis that an upswing in violence occurs about once every generation to a generation and a half, if one assumes some change in the life spans making up the "generation."

\section{0- TO 120-YEAR CYCLE}

While it is necessary to have a relatively short observation time to examine the data for the expected 25-year cycle, it is desirable to average out these fluctuations when examining the data for longer-term trends. Such an averaging makes visual observation easier; that is, short-term fluctuations are masked in order to give a more ordered appearance to the longer fluctuations. The amount-of-war index values are averaged over four periods ( 20 years) in Figure 4.

A pattern similar to that postulated is exhibited by these data. Throughout the period of the data a consistent rise in the level of violence is exhibited for several years (a minimum of 60 years-a maximum of 120 years). A sharp decline is noted after each rise and the decline is in each case followed by another rise in violence. The dashed curve indicates an extrapolation using Richardson's data for the first half of the 20th century.

How significant, statistically, is this visually detectable pattern? That is, could a pattern of this nature result by random chance? The original hypothesis is formulated in nonoperational terms. The prime expected effect is that periods of high violence will be followed by a decrease in violence and that periods of low violence will be followed by an increase in violence. Operationally the hypothesis may be expressed by two statements:

(1) Periods of high violence in the system will be followed by a decrease in the level of violence.

(2) Periods of low systemic violence will be followed by an increase in violence.

These hypotheses imply a system in which conflict (manifested in violence)

TABLE 6

Thirty-Year Cycle-Post-1680

\begin{tabular}{lrrrrrr}
\hline \hline & \multicolumn{7}{c}{ Number of periods } \\
\hline Above mean & 5 & 6 & 3 & 1 & 3 & 4 \\
Below mean & 3 & 2 & 4 & 6 & 4 & 3 \\
& 1685 & 1690 & 1695 & 1700 & 1705 & 1710 \\
$\begin{array}{l}\text { Average value of } \\
\text { amount-of-war }\end{array}$ & .04 & .58 & -.39 & -.59 & -.03 & .09 \\
\hline
\end{tabular}




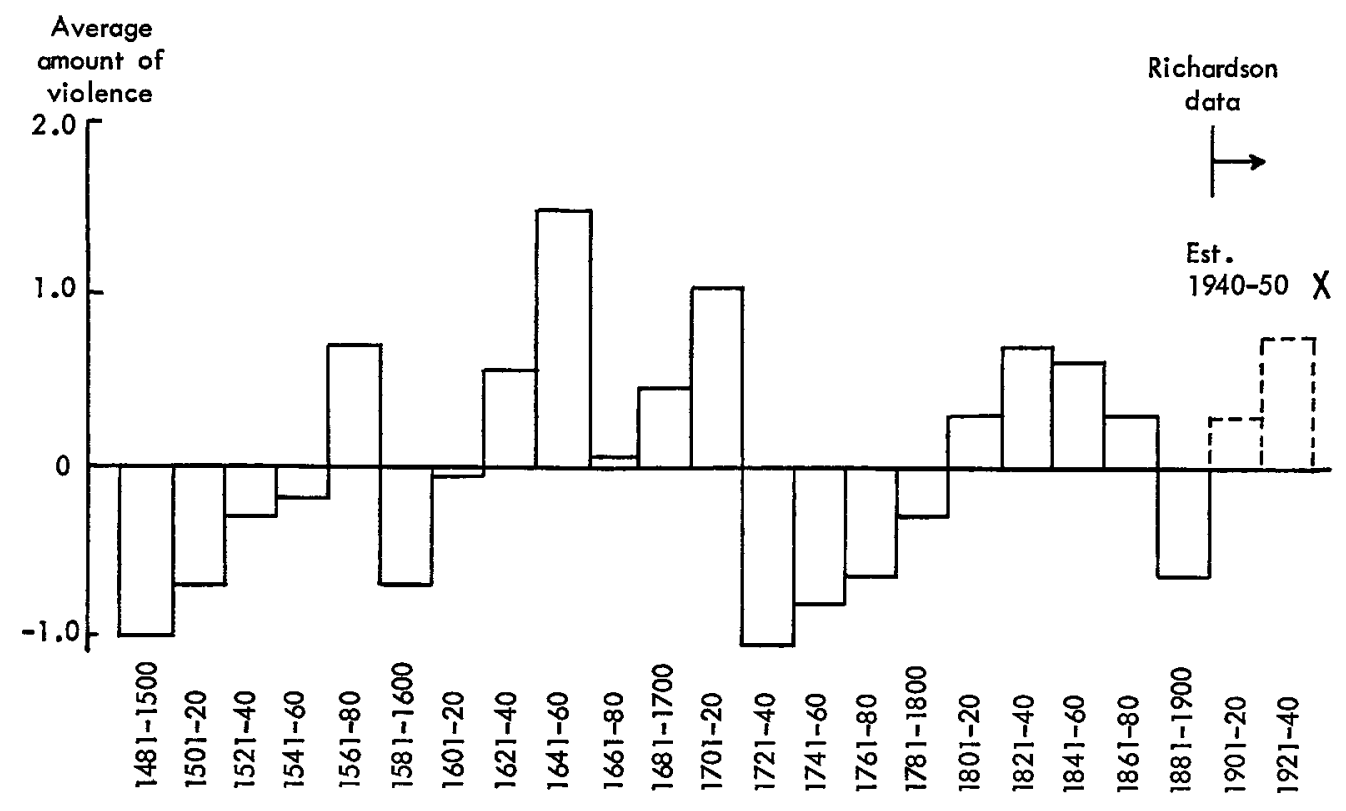

FIG. 4. 80 - to 120-year cycle.

grows in scale until a reaction against violence per se occurs. This reaction results in lower conflict in the system until conditions permit the growth of new conflict.

The only remaining problem in operationalizing the hypothesis is to select a level above which violence will be considered high. The mean is one obvious "level" for this purpose. "High violence," on the other hand, intuitively implies a condition somewhat above average, that is, more than just barely above the mean. Two levels of "high" are tested to determine if the results differ depending on how high "high" is.

(1) In the first case, "high" violence is defined as above the mean (a 20-year average of the size index). Below the mean is defined as "low" violence.

(2) In the second case, "high" violence is defined as more than half a standard deviation above the mean. "Low" violence is below this value. This test is perhaps more consistent with the original hypothesis. The cushion of half a standard deviation eliminates from the "high" violence category those time periods with only slightly greater than average violence.

For both definitions, as we see in Table 7 , periods of high violence are usually followed by a decrease in violence and periods of low violence by an increase. The division of high at half a standard deviation above the mean gives a pattern with only two of 20 periods deviating from the expected trend.

Previous research indicated a correlation between high violence and the prevalence of civil conflict (Denton, 1966). Checking on these data it is found that, across the 84 five-year observations, the indicator involving the percent of wars that are civil wars correlates .39 with the size-of-war indicator. For 84 observations a product moment correlation of .39 (two-tailed test) is significant at about the .01 level. Figure 5 shows a plot of the 20-year average of percent civil war versus the amount-of-war values for the same intervals. The correla- 
TABLE 7

LEVELS OF VIOLENCE AND INCREASE or Dechease in Next Period

1)

$\begin{array}{ccc}\text { Period with } & \begin{array}{c}\text { Increase in } \\ \text { Violence }\end{array} & \begin{array}{c}\text { Decrease in } \\ \text { Violence }\end{array} \\ \text { High } & & 6 \\ \text { Violence* } & 4 & \\ \text { Low } & & 0\end{array}$

Fisher exact test Significance: $\approx .025$

2)

Next Period

$\begin{array}{ccc}\begin{array}{c}\text { Period with } \\ \text { High }\end{array} & \begin{array}{c}\text { Increase in } \\ \text { Violence }\end{array} & \begin{array}{c}\text { Decrease in } \\ \text { Violence }\end{array} \\ \begin{array}{l}\text { Violence** } \\ \text { Low }\end{array} & 1 & 5 \\ \begin{array}{l}\text { Violence } \\ \text { Fisher exact test Significance: } \approx .005\end{array}\end{array}$

* "High" defined as above the mean (20-year average of size index).

** "High" defined as more than half a standard deviation above the mean. tion is obviously even higher when the longer time periods are used. Thus, periods in which there is much war are quite consistently periods which exhibit a relatively high frequency of civil wars. In addition to supporting the hypothesis about a longterm cyclical trend in violence, the data also support the postulate that those periods of intense conflict are associated with social change or turmoil, as indicated by a concomitant relatively high frequency of civil conflict.

\section{Summary and Conclusions}

The primary purpose in this analysis is to test for the existence of two postulated cyclical trends in the historical record of violence. The data generally support the hypotheses. That is, evidence of cyclical patterns exists in the historical data.

Why such patterns and what are the

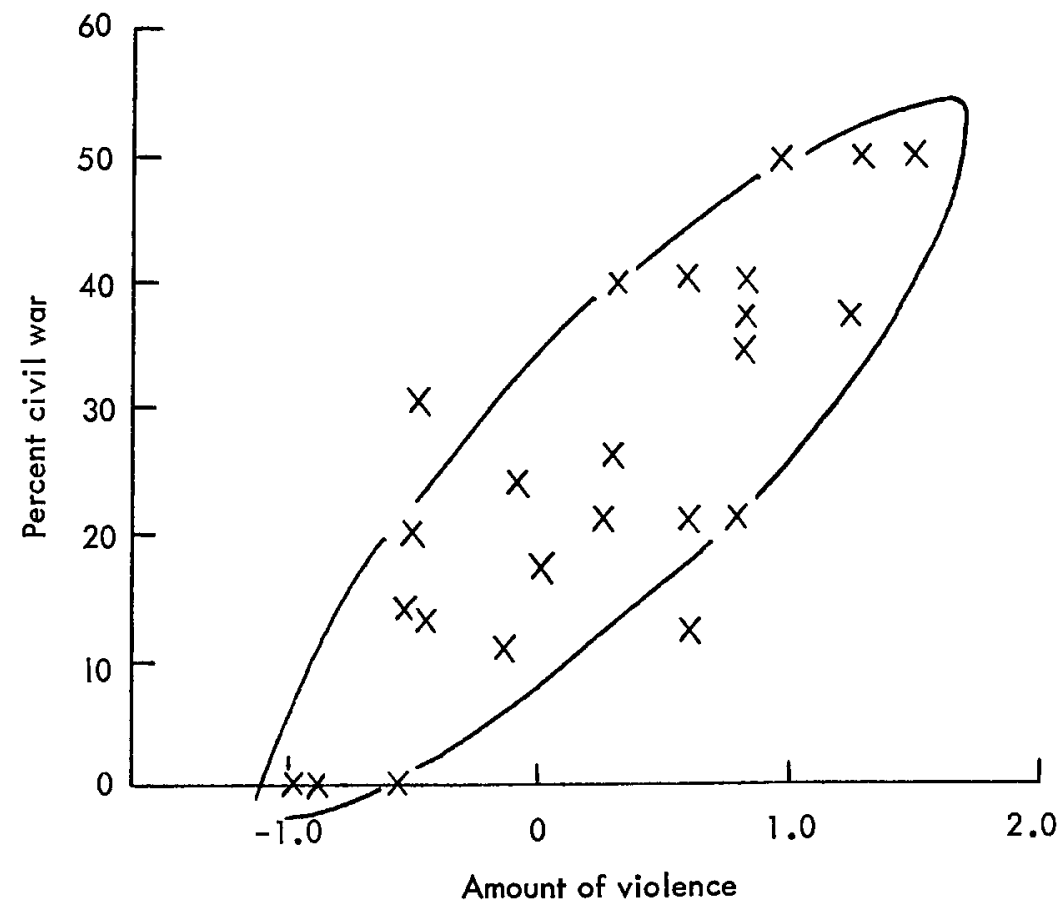

FIG. 5. Percent of civil war versus amount of war (20-year averages). 
theoretical implications? Some speculation about the "why" was made in the earlier formulation of the hypotheses. Although the data give few direct clues for going beyond the empirical description to an explanation, it does seem appropriate to discuss possible explanations which might be tested.

Hypothesis 1 suggested an upswing in the level of violence about every 25 years. The data support such a general trend with 20 years providing a "best" fit prior to 1680 and about 30 years thereafter. ${ }^{9}$ Others have alluded to a generation effect in decisionmaking, or a fading into the past of the last war as a permissive condition for future war. Several conditions may be associated with such a periodic increase in violence:

(1) Immediately following an intense war the public remembrance of it is of the horrors, the human suffering, the dislocations. The "horror" remembrance may be reinforced by the memoirs, biographies, novels, or fireside stories written and told by first-hand participants while their own experiences are fresh. At the same time, the glory of defending the fatherland, the adventure, and the grim humor of war are themes which are often expressed. Perhaps, through a defense against the distasteful, the "horror" is suppressed as memories age and as an increasing number of society's members have not had first-hand exposure to violence. On the other hand, the requirement ${ }^{10}$ for ensuring willingness to defend the state or society against intruders motivates many to further glorify "dying for one's country." Thus the themes employed in the descriptions of the last great war shift from "horror"-dominant to "glory"-

\footnotetext{
${ }^{9}$ The process of grouping five-year intervals somewhat limits the accuracy of these statements.

${ }^{10}$ Some might go further and say man's inherent evil.
}

dominant. ${ }^{11}$ This shift is then tied to the human life cycle of 20 to 30 years.

Such an hypothesis could be easily tested by examining the frequency of the above themes in the public literature at various times after major conflicts.

(2) Perhaps even more important would be the application of a similar thesis to decision-makers. Subjectively, it seems that major conflicts have created the next generation of decision-makers. Thus, for a number of years after major conflicts, the system's decision-makers have had first-hand experience with violence. Decision-makers seldom obtain power before they are 40 to 45 and seldom retain power beyond 65 to 70. A new, "unsullied" group of decisionmakers gradually comes into power after the conflict. A generation's time sees almost a complete turnover.

By examining the records of the accession to office of decision-makers, and by comparing the attitudes of "war responsible" decision-makers toward the use of violence with those of the new generation without war responsibility, it would be possible to test such an explanation.

(3) Implicit in the above explanations is an assumption that the opportunities for employing violence are always present. The only condition necessary for violence is the willingness to become engaged. However, Richardson for one has shown that there is an indication of continuity in conflict. In fact, he goes on to explain this continuity in terms of a generation effect (1960, p. 200) :

We may suppose that the generation who had not fought in the earlier war, but who were brought up on tales about its romance, heroism, and about the wickedness of the enemy, became influential 30 to 60 years after the war ended and so delayed the process of forgetting

${ }^{11}$ Today's TV programs on World War II seem rather "humor"-dominant. 
and forgiving [Richardson observed an increase in retaliatory and revenge wars 30 to 60 years after the original conflict].

Thus, a third effect of continuity of conflict and hatred may exacerbate the above trends. A planned research project will involve the investigation of continuity in alliance and conflict patterns.

The generation effect was a priori a "reasonable" explanation. The longer-term cycle is, in the minds of the authors, a pattern which is not as easily explained on intuitive grounds. It appears that one promising explanation is offered by an action-reaction process in political philosophy (taken in the broad sense to include the general attitude of the elites ${ }^{\mathbf{1 2}}$ toward the "correct" society). Man seems to strive both for a better society and for more security in those desirable aspects of the present society. As previously noted, periods of intense violence are typified without exception by a relatively high frequency of civil conflict. This would, of course, indicate dissatisfaction with the form of society. Moreover, periods of intense conflict are consistently followed by periods of low violence with a very low frequency of civil violence.

It seems logical to expect that philosophies of change are associated with periods of intense civil violence. The religious controversies of the 16th and 17th centuries, the French and European revolutions of the late 18th and early 19th centuries, and the Communist revolutions of this century are all associated with philosophies of change. A reasonable hypothesis could be made that, in a given society, the relative weight given to the desire for improving society as opposed to maintaining society is dependent on the conditions of

\footnotetext{
${ }^{12}$ In the abstract sense, those who influence and/or make decisions.
}

(1) rate of change and (2) discrepancy between the actual and the ideal society.

Thus, first, conditions of rapid change, associated with high tensions and violence, induce philosophic positions emphasizing the importance of an orderly society and philosophies glorifying the traditional strengths of the established system. That is, insecurity leads to emphasizing the desire for maintenance of the good aspects of an idealized society of the past. ${ }^{13}$

Second, periods of stability reduce the experience and thus the fear of insecurity. Moreover, it seems intuitively true that there is almost always a discrepancy between the real and ideal form of society. It may even be true that periods of social stability (slow change) increase this discrepancy. That is, to use an old adage, "them that has gets." Philosophers, freed from the need to emphasize order in an already orderly society, concentrate on the need for reducing the discrepancy between the real and the ideal.

The result of these hypotheses is that change tends to be followed by stability, by change again, and so on. The period of the cycle (averaging about a century in length), while it is not intuitively obvious, does not seem unreasonable. Truths die slowly and perhaps the passage of several generations is needed to tilt the scales.

${ }^{13}$ George Sabine in his History of Political Theory explicitly discusses philosophic reactions against violence, though not the reverse. Sabine states that Bodin's "divine right of kings" could be considered as a reaction against the instability and violence of the religious wars ( $p$. 399). He also describes Burke's decision to codify his philosophy as " . . the beginning of a shift ... [in] social philosophy from attack to defense and ... to an emphasis on the value of stability . . ." as the result of the French Revolution (p. 617). In our own time the conservative reaction to instability and change seems to gather greater strength with more change. 
A systematic examination of themes in philosophic positions could provide a test of this hypothesis. These data provide onehalf the objective situation, that of violence and social disruption. It might also be worthwhile to determine, as possible, if periods of slow change do increase the discrepancy between real and ideal.

Obviously the above explanations go beyond the data. However, it is believed that they are consistent with the patterns exhibited in the history of violence. Moreover, if the explanations are useful models they provide a framework for a theoretical explanation of certain changes in the international (or perhaps more appropriately the interpolitical group) system. ${ }^{14}$

In addition to the limitations on our explanations, the assumption that violence

${ }^{14}$ In order to (try to) escape the label of "historical determinist" let us offer the following position statement. It is not felt that patterns in history absolutely determine the future. However, it is felt, because of historical learning, ongoing environmental factors, and certain regularities in man's behavioral structure, that he is partially a product of his past. While individually man may enjoy "free will," be "adaptive," etc., as a group he is conservative and not very adaptive, at least in the short run. Even if faced with the "truth" of a needed revision in beliefs he (and a number of his prophets) is perfectly capable of "rationally" showing that the old ways are best. And who is going to give him the truth? On the other hand, there is obviously a long-term learning process which may change such factors. reflects the political issues of the day may be questioned by some. ${ }^{15}$ Beyond this, the data are not complete (there is some discrepancy between the Wright and Richardson data for the period in which they overlap). The possible effects of improved data are, of course, not known.

\section{REFERENCES}

Denton, Frank H. "Some Regularities in International Conflict, 1820-1949," Background, 9, 4 (Feb. 1966), 283-96.

Jones, Ronald D. Construct Mapping. Kansas City: University of Missouri, mimeographed, June 1966.

Moyal, J. E. "The Distribution of Wars in Time," Journal of the Royal Statistical Society, 112 (1949), 446-58.

Richardson, Lewis F. Statistics of Deadly Quarrels. Pittsburgh: Boxwood Press, 1960.

Rosecrance, Richard N. Action and Reaction in World Politics. Boston: Little, Brown, 1963.

Sabine, George H. A History of Political Theory. New York: Holt, Rinehart and Winston, 1961.

Singer, J. David, Melvin Small, and George L. Kraft. The Frequency, Magnitude, and Severity of International War, 1815-1940. Ann Arbor: Mental Health Research Institute Preprint 158, University of Michigan, July 1965.

Sorokin, PitrRim. Social Change and Cultural Dynamics. Boston: Porter Sargent, 1957.

Wright, Quincy. A Study of War. Chicago: University of Chicago Press, 1942.

${ }^{15}$ The pattern of violence (Figure 4 ) does seem to reflect known historical trends, however. 